\title{
A convenient method for the synthesis of hydroxymethyl and carboxaldehyde derivatives of 3,5-diphenyl-4H-pyran-4-one
}

\author{
Reza Teimuri-Mofrad* and Fatemeh Abrishami \\ Department of Chemistry, Faculty of Materials, Malek-ashtar University of Technology, Tehran, \\ P O. Box 16765-3454, Iran \\ E-mail:teimuri@mut.ac.ir
}

\begin{abstract}
A convenient method was developed for the synthesis of hydroxymethyl and carboxaldehyde derivatives of 3,5-diphenyl-4H-pyran-4-one from their corresponding bromomethyl derivatives by treatment with silver acetate followed by hydrolysis and oxidation. Compounds, 3,5-diphenyl2-hydroxymethyl-6-methyl-4H-pyran-4-one (4a), 2,6-bishydroxymethyl-3,5-diphenyl-4H-pyran4-one (7a), 3,5-diphenyl-6-methyl-4-oxo-4H-pyran-2-carboxaldehyde (3a), and 3,5-diphenyl-4oxo-4H-pyran-2,6-dicarboxaldehyde (6a) were obtained.
\end{abstract}

Keywords: 4H-Pyran-4-one, hydroxymethyl and carboxaldehyde derivatives, hydrolysis, oxidation

\section{Introduction}

4H-Pyran-4-one derivatives constitute a useful class of heterocyclic compounds, which are widely distributed in nature ${ }^{1-3}$. These compounds display diverse biological functions, acting as fungicides and herbicides, and a variety of pharmacological applications, which could be useful in the treatment of asthma and allergies ${ }^{4-6}$.

Functionalized heterocycles are often used for the synthesis of target organic compounds. Many new methods for their synthesis have been reported ${ }^{7-10}$. Some $4 H$-pyran-4-ones containing a carboxaldehyde group may be prepared by oxidation of a hydroxymethyl group in derivatives of kojic acid ${ }^{11-13}$, formylation of pyrones in the presence of trifluoroacetic acid ${ }^{14}$, and condensation of a methyl group at positions 2 and 6 of $4 \mathrm{H}$-pyran-4-one derivatives with an aldehyde, followed by oxidation of the resultant styryl group by $\mathrm{OsO}_{4}$ and $\mathrm{KIO}_{4}{ }^{9}$ (Scheme 1).

Some of the $4 H$-pyran-4-ones containing a hydroxymethyl group can be prepared by fermentation $^{11}$, e.g. kojic acid, but 2 and 6-hydroxymethyl substituted 3,5-diphenyl-4H-pyran-4one derivatives 4a, 7a were first prepared in 2002 by Ghandi and coworkers ${ }^{9}$ through reduction of the corresponding carboxaldehyde derivatives of 3,5-diphenyl-4H-pyran-4-one (3a, 6a), with 
sodium borohydride in 76 and 69\% yields, respectively (Scheme 1).

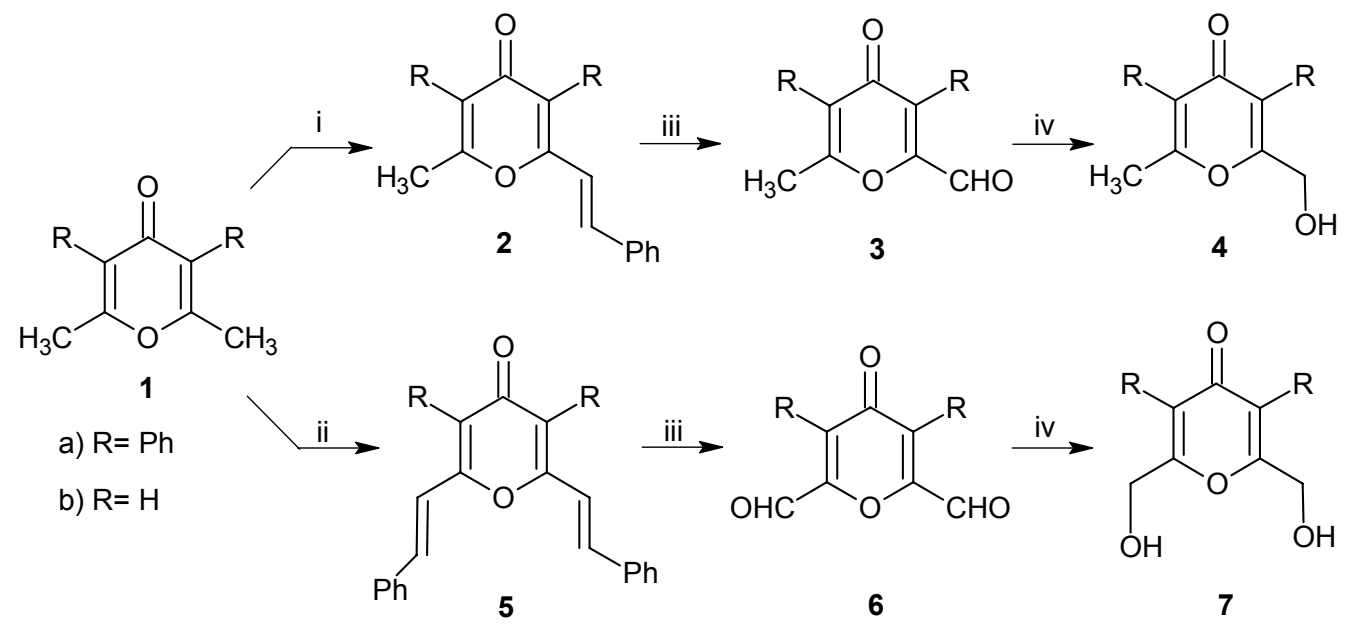

Scheme 1. (i) $\mathrm{PhCHO}, \mathrm{NaOEt}$, (ii) $2 \mathrm{PhCHO}, 2 \mathrm{NaOEt}$, (iii) $\mathrm{OsO}_{4}, \mathrm{KIO}_{4}$, (iv) $\mathrm{NaBH}_{4}$

Exploring efficient methods for the synthesis of hydroxymethyl and carboxaldehyde derivatives of $4 \mathrm{H}$-pyran-4-ones is an important topic because these compounds are potentially useful as intermediates for the synthesis of a number of $4 H$-pyran-4-one derivatives. For example, host macrocycles could be obtained from their bishydroxymethyl and dicarboxaldehyde derivatives.

We wish to report a convenient method for the synthesis of hydroxymethyl and carboxaldehyde derivatives of 3,5-diphenyl-4H-pyran-4-one substituted at positions 2 and 6, viz. compounds 3a, 4a, 6a, and 7a, from their corresponding bromomethyl derivatives.

\section{Results and Discussion}

2,6-Bisbromomethyl-3,5-diphenyl-4H-pyran-4-one (9) was first prepared in 1990 by Massa and coworkers $^{15}$ through bromination of 2,6-dimethyl-3,5-diphenyl-4H-pyran-4-one (1a) ${ }^{16}$ with $\mathrm{N}$ bromosuccinimide in 56\% yield. As a result, we attempted to synthesize 2-bromomethyl-3,5diphenyl-6-methyl-4H-pyran-4-one (8) by means of Wohl-Ziegler bromination ${ }^{17}$. Bromination was performed by reaction of compound 1a with 1.1 equivalent of $N$-bromosuccinimide in the presence of dibenzoyl peroxide in tetrachloromethane and compound $\mathbf{8}$ was obtained in $68 \%$ yield (Scheme 2).

It is often necessary in organic synthesis to convert alcohols into alkyl halides, but only occasionally is it necessary to achieve the reverse conversion, i.e. the hydrolysis of alkyl halides. As a consequence, relatively few reagents have been developed for this purpose ${ }^{18}$. The more reactive alkyl halides, i.e. tertiary, benzyl and allyl halides, can be hydrolysed easily by water in various solvents $^{18}$ or by aqueous bicarbonate ${ }^{19}$. However, the hydrolysis of primary alkyl halides 
is more difficult and has usually been achieved using alkali metal hydroxides ${ }^{18}$, though in a few simple cases it has been shown that water in $N$-methylpyrrolidone or hexamethylphosphoramide can achieve hydrolysis ${ }^{20}$. Primary bromides and iodides have also been hydrolysed using bis(tributyltin) oxide in the presence of silver salts ${ }^{21}$, however, the $4 H$-pyran-4-one ring is unstable under basic conditions, therefore, direct substitution of halide by a hydroxyl group is not possible. We performed the conversion of bromomethyl groups smoothly to hydroxymethyl groups under conditions that would not open the ring of $4 H$-pyran-4-one molecule. Thus, treatment of the bromomethyl derivatives, compounds $\mathbf{8}$ and $\mathbf{9}$, with silver acetate in glacial acetic acid $^{22}$ produced the corresponding acetoxymethyl derivatives, compounds $\mathbf{1 0}$ and $\mathbf{1 1}$, in 93 and $91 \%$ yields, respectively. We also achieved these conversions using potassium fluoride in acetic acid $^{23}$ in 61 and 58\% yields, respectively. Acidic hydrolysis $\left(\mathrm{HCl}: \mathrm{THF}: \mathrm{H}_{2} \mathrm{O}\right)$ of compounds 10 and 11 produced compounds $\mathbf{4 a}$ and 7a, in 93 and 91\% yields, respectively (Scheme 2).
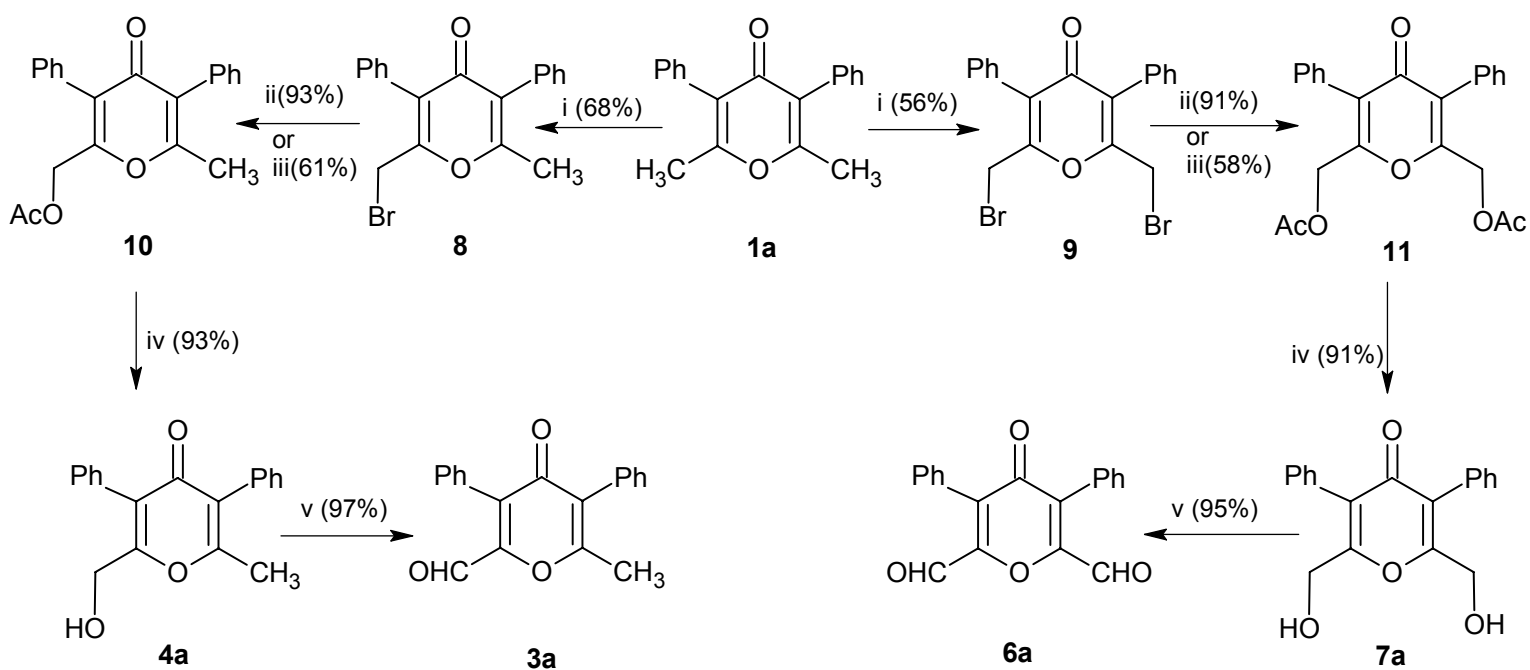

Scheme 2. (i) NBS, BPO/CCl 4 (refluxing temp., 48 h). (ii) AgOAc/AcOH (refluxing temp., 4 h). (iii) $\mathrm{KF} / \mathrm{AcOH}$ (refluxing temp., 16 h). (iv) $\mathrm{HCl}$ : THF: $\mathrm{H}_{2} \mathrm{O}$ (0.05:2:1) (refluxing temp., $24 \mathrm{~h}$ ). (v) $\mathrm{BaMnO}_{4}, \mathrm{CH}_{2} \mathrm{Cl}_{2} / \mathrm{THF}$ (room temp., $2 \mathrm{~h}$ ).

Recently Ghandi and coworkers have converted methyl derivatives of $4 H$-pyran-4-ones to the corresponding styryl derivatives, which afforded the carboxaldehyde derivatives by oxidative cleavage 9 . Accordingly, we decided to oxidize the mono and bishydroxymethyl groups in compounds $\mathbf{4 a}$ and $7 \mathbf{a}$ to the corresponding carboxaldehyde groups with barium permanganate in dichloromethane and THF at room temperature. Compounds 3a and 6a were obtained in 97 and $95 \%$ yields, respectively.

Data obtained from mass spectra, IR, ${ }^{1} \mathrm{H}$ and ${ }^{13} \mathrm{C}$ NMR spectra and elemental analyses are fully consistent with the proposed structures. 


\section{Experimental Section}

General Procedures. Melting points were determined with an Electrothermal Instrument model 9100 and are uncorrected. Infrared (IR) spectra were run on a Shimadzu FT-IR 4300 Spectrophotometer as $\mathrm{KBr}$ disks or as smears between salt plates. The ${ }^{1} \mathrm{H}$ NMR spectra were recorded on a Varian $300 \mathrm{MHz}$ spectrometer. The ${ }^{13} \mathrm{C}$ NMR spectra were determined on a FTNMR Brucker $100 \mathrm{MHz}$ spectrometer. Chemical shifts $(\delta)$ were reported in values in ppm with TMS as internal standard. Mass spectra were taken with a Shimadzu MS-QP 1100 EX mass spectrometer. Elemental analyses were performed on a Heareus, CHN-O-RAPID analyzer.

2,6-Dimethyl-3,5-diphenyl-4H-pyran-4-one (1a). Compound 1a was prepared according to literature ${ }^{16}$ in $45 \%$ yield as pale brown crystals, $\mathrm{mp} 203^{\circ} \mathrm{C}\left(\right.$ lit. $^{16} 204^{\circ} \mathrm{C}$ ).

2-Bromomethyl-3,5-diphenyl-6-methyl-4H-pyran-4-one (8). A mixture of $5 \mathrm{~g}(18.1 \mathrm{mmol})$ of compound 1a, $3.54 \mathrm{~g}(19.9 \mathrm{mmol})$ of N-bromosuccinimide, $0.05 \mathrm{~g}$ of dibenzoyl peroxide and 30 $\mathrm{mL}$ of tetrachloromethane was refluxed for $48 \mathrm{~h}$. The reaction mixture was filtered after cooling. The separated solid was heated at $50-60^{\circ} \mathrm{C}$ in $230 \mathrm{~mL}$ of aqueous ethanol $(5 \% \mathrm{EtOH})$ for 30 minutes. After cooling, the precipitate was filtered, washed with cold ethanol and recrystallized from $95 \%$ ethanol to give white crystals $(68 \%)$; mp 176.1-177. $8^{\circ} \mathrm{C}$. Anal. Calcd. for $\mathrm{C}_{19} \mathrm{H}_{15} \mathrm{BrO}_{2}$ : C, 64.24\%; H, 4.26\%. Found: C, 64.5\%; H, 4.3\%. MS (EI, $70 \mathrm{ev}$ ): $\mathrm{m} / \mathrm{z} 356 / 354\left(\mathrm{M}^{+}\right)$. IR: 1582 , 1600, 1630, 2925 and $3005 \mathrm{~cm}^{-1} .{ }^{1} \mathrm{H}$ NMR $\left(\mathrm{CDCl}_{3}\right): \delta 2.20\left(3 \mathrm{H}, \mathrm{s},-\mathrm{CH}_{3}\right), 4.13\left(2 \mathrm{H}, \mathrm{s},-\mathrm{CH}_{2} \mathrm{Br}\right)$, 7.15-7.33 (10H, m, Phenyl-H). ${ }^{13} \mathrm{C}$ NMR $\left(\mathrm{CDCl}_{3}\right): \delta 16.0\left(-\mathrm{CH}_{3}\right), 26.0\left(-\mathrm{CH}_{2} \mathrm{Br}\right), 123.0$ (PyranC-5), 128.0 (Pyran-C-3), 128.5-130.0 (m, Phenyl-C), 157.0 (Pyran-C-6), 159.0 (Pyran-C-2), 176.5 (Pyran-C-4).

2,6-Bisbromomethyl-3,5-diphenyl-4H-pyran-4-one (9). Compound 9 was synthesized according to literature ${ }^{15}$ in $56 \%$ yield as white crystals; mp $215.5-216.8^{\circ} \mathrm{C}\left(\right.$ lit. $^{15} 216-217^{\circ} \mathrm{C}$ ).

\section{General Procedure for The Acetoxylation of Compounds 8 and 9.}

Method A. A mixture of $4 \mathrm{mmol}$ of compound 8 or $2 \mathrm{mmol}$ of compound $\mathbf{9}, 0.74 \mathrm{~g}(4.4 \mathrm{mmol})$ of silver acetate and $15 \mathrm{~mL}$ of glacial acetic acid was refluxed for $4 \mathrm{~h}$. The mixture was filtered and $50 \mathrm{~mL}$ of water was added to the filtrate and the mixture was extracted with $3 \times 15 \mathrm{~mL}$ of $\mathrm{CH}_{2} \mathrm{Cl}_{2}$. Combined organic layer was washed with $3 \times 10 \mathrm{~mL}$ of $\mathrm{H}_{2} \mathrm{O}$, dried over $\mathrm{MgSO}_{4}$ and the solvent was removed under reduced pressure. Specific details are given for each compound.

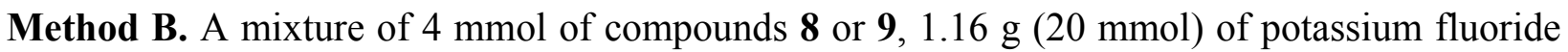
and $10 \mathrm{~mL}$ of glacial acetic acid was refluxed for $16 \mathrm{~h}$. After cooling, $30 \mathrm{~mL}$ of water was added and the mixture was extracted with $3 \times 10 \mathrm{~mL}$ of $\mathrm{CH}_{2} \mathrm{Cl}_{2}$. Combined organic layer was washed with $3 \times 10 \mathrm{~mL}$ of $\mathrm{H}_{2} \mathrm{O}$ and dried over $\mathrm{MgSO}_{4}$. The solvent was evaporated in vacuo. The residue was chromatographed on silica gel with ethyl acetate - petroleum ether (3:7) as eluent. Specific details are given for each compound.

2-Acetoxymethyl-3,5-diphenyl-6-methyl-4H-pyran-4-one (10). Method A: $1.42 \mathrm{~g}$ of compound 8 gave $\mathbf{1 0}(1.24 \mathrm{~g}, 93 \%)$ as a colorless oil. Anal. Calcd. for $\mathrm{C}_{21} \mathrm{H}_{18} \mathrm{O}_{4}: \mathrm{C}, 75.43 \% ; \mathrm{H}$, 5.42\%. Found: C, 76.69\%; H, 5.29\%. MS (EI, $70 \mathrm{ev):} \mathrm{m} / \mathrm{z} 334\left(\mathrm{M}^{+}\right)$. IR: 1631, 1746 and 3054 
$\mathrm{cm}^{-1} .{ }^{1} \mathrm{H}$ NMR $\left(\mathrm{CDCl}_{3}\right): \delta 2.05\left(3 \mathrm{H}, \mathrm{s}, \mathrm{CH}_{3} \mathrm{COO}-\right), 2.22\left(3 \mathrm{H}, \mathrm{s},-\mathrm{CH}_{3}\right), 4.80\left(2 \mathrm{H}, \mathrm{s},-\mathrm{CH} \mathbf{H}_{2} \mathrm{O}\right)$, $7.32\left(10 \mathrm{H}, \mathrm{s}\right.$, Phenyl-H). ${ }^{13} \mathrm{C}$ NMR $\left(\mathrm{CDCl}_{3}\right): \delta 18.6\left(-\mathrm{CH}_{3}\right), 20.4\left(\mathbf{C H}_{3} \mathrm{COO}-\right), 61.0\left(-\mathrm{CH}_{2} \mathrm{O}-\right)$, 127.0 (Pyran-C-5), 127.6 (Pyran-C-3), 128.0, 128.5, 130.0, 130.8 and 132.2 (Phenyl-C), 158.8 (Pyran-C-6), 162.2 (Pyran-C-2), 169.7 ( $\left.\mathrm{CH}_{3} \mathrm{COO}-\right), 176.3$ (Pyran-C-4).

Method B: $1.42 \mathrm{~g}$ of compound 8 gave $10(0.82 \mathrm{~g}, 61 \%)$ as a colorless oil with similar physical and spectral properties.

2,6-Bisacetoxymethyl-3,5-diphenyl-4H-pyran-4-one (11). Method A: $0.87 \mathrm{~g}$ of compound 9 gave $11(0.71 \mathrm{~g}, 91 \%)$ as a yellow oil. Anal. Calcd. for $\mathrm{C}_{23} \mathrm{H}_{20} \mathrm{O}_{6}: \mathrm{C}, 70.4 \%$; $\mathrm{H}, 5.14 \%$. Found: C, 70.81\%; H, 5.31\%. MS (EI, $70 \mathrm{ev):} \mathrm{m} / z 392\left(\mathrm{M}^{+}\right)$. IR: 1631, 1754 and $3023 \mathrm{~cm}^{-1}$. ${ }^{1} \mathrm{H}$ NMR $\left(\mathrm{CDCl}_{3}\right): \delta 2.08\left(6 \mathrm{H}, \mathrm{s}, \mathrm{CH}_{3} \mathrm{COO}-\right), 4.90\left(4 \mathrm{H}, \mathrm{s},-\mathrm{CH}_{2} \mathrm{O}-\right), 7.35\left(10 \mathrm{H}, \mathrm{s}\right.$, Phenyl-H). ${ }^{13} \mathrm{C}$ NMR $\left(\mathrm{CDCl}_{3}\right): \delta 20.0\left(\mathrm{CH}_{3} \mathrm{COO}-\right), 60.0$ (-CH $\left.\mathrm{CH}_{2} \mathrm{O}-\right)$, 128.0 (Pyran-C-3,-5), 128.3, 128.5, 129.9 and 130.3 (Phenyl-C), 157.5 (Pyran-C-2,-6), 170.0 ( $\left.\mathrm{CH}_{3} \mathrm{COO}-\right)$, 177.0 (Pyran-C-4).

Method B: $1.74 \mathrm{~g}$ of compound 9 gave $11(0.91 \mathrm{~g}, 58 \%)$ as a yellow oil with similar physical and spectral properties.

3,5-Diphenyl-2-hydroxymethyl-6-methyl-4H-pyran-4-one (4a). A mixture of $1.67 \mathrm{~g}$ (5 mmol) of compound 10, $25 \mathrm{~mL}$ THF, $12.5 \mathrm{~mL}$ of water and $0.6 \mathrm{~mL}$ concentrated hydrochloric acid was refluxed for $24 \mathrm{~h}$. THF was removed under reduced pressure and $10 \mathrm{~mL}$ of water was added and the mixture was extracted with $3 \times 15 \mathrm{~mL}$ of $\mathrm{CH}_{2} \mathrm{Cl}_{2}$. Combined organic layer was washed with $3 \times 15 \mathrm{~mL}$ of $\mathrm{H}_{2} \mathrm{O}$ and dried over $\mathrm{MgSO}_{4}$. The solvent was evaporated in vacuo and $1.36 \mathrm{~g}$ white crystals were obtained in $93 \%$ yield; $\mathrm{mp} 217.2-219.0{ }^{\circ} \mathrm{C}$. Anal. Calcd. for $\mathrm{C}_{19} \mathrm{H}_{16} \mathrm{O}_{3}$ : $\mathrm{C}, 78.06 \%$; H, 5.52\%. Found: C, 78.55\%; H, 5.69\%. MS (EI, $70 \mathrm{ev):} \mathrm{m} / \mathrm{z} 292\left(\mathrm{M}^{+}\right)$. IR: 1588, 1657 and 3362 (br) $\mathrm{cm}^{-1} .{ }^{1} \mathrm{H}$ NMR $\left(\mathrm{CDCl}_{3}\right): \delta 2.40\left(3 \mathrm{H}, \mathrm{s},-\mathrm{CH}_{3}\right), 2.45\left(\mathrm{lH}, \mathrm{br},-\mathrm{CH}_{2} \mathrm{OH}\right), 4.50\left(2 \mathrm{H}, \mathrm{s},-\mathrm{CH} \mathbf{H}_{2} \mathrm{OH}\right)$, $7.48\left(10 \mathrm{H}, \mathrm{s}\right.$, Phenyl-H). ${ }^{13} \mathrm{C}$ NMR $\left(\mathrm{CDCl}_{3}\right): \delta 19.8\left(-\mathrm{CH}_{3}\right), 59.5\left(-\mathrm{CH}_{2} \mathrm{O}-\right), 126.8$ (Pyran-C-5), 127.8 (Pyran-C-3), 128.5, 128.9, 130.2, 130.6 and 131.8 (Phenyl-C), 158.5 (Pyran-C-6), 161.9 (Pyran-C-2), 176.2 (Pyran-C-4).

2,6- Bishydroxymethyl-3,5-diphenyl-4H-pyran-4-one (7a). A mixture of $1.96 \mathrm{~g}$ (5 mmol) of compound 11, $50 \mathrm{~mL}$ THF, $25 \mathrm{~mL}$ water and $1.2 \mathrm{~mL}$ concentrated hydrochloric acid was refluxed for $24 \mathrm{~h}$. THF was removed under reduced pressure. The mixture was cooled and neutralized with $\mathrm{NaHCO}_{3}$ to $\mathrm{pH}$ 7. The mixture was concentrated under reduced pressure and the residue after complete drying was extracted with several portions of $\mathrm{MeOH}$. Combined organic solution was concentrated in vacuo. $1.4 \mathrm{~g}$ white crystals were obtained in 91\% yield; mp 231.4$232.8{ }^{\circ} \mathrm{C}$. Anal. Calcd. for $\mathrm{C}_{19} \mathrm{H}_{16} \mathrm{O}_{4}$ : C, 74.01\%; H, 5.23\%. Found: C, 74.5\%; H, 5.34\%. MS (EI, $70 \mathrm{ev}): m / z 308\left(\mathrm{M}^{+}\right)$. IR: 1580, 1650 and 3401(br) $\mathrm{cm}^{-1} .{ }^{1} \mathrm{H}$ NMR $\left(\mathrm{CDCl}_{3}\right): \delta 2.80(2 \mathrm{H}, \mathrm{s},-$ $\left.\mathrm{CH}_{2} \mathrm{OH}\right), 4.30\left(4 \mathrm{H}, \mathrm{s},-\mathrm{CH}_{2} \mathrm{OH}\right), 7.10-7.50\left(10 \mathrm{H}, \mathrm{m}\right.$, Phenyl-H) ${ }^{13} \mathrm{C}$ NMR $\left(\mathrm{CDCl}_{3}\right): \delta 58.5(-$ $\mathrm{CH}_{2} \mathrm{O}-$ ), 128.5 (Pyran-C-3, -5), 128.0-131.0 (m, Phenyl-C), 157.0 (Pyran-C-2, -6), 176.5 (PyranC-4).

\section{General procedure for synthesis of $3 a$ and $6 a$}

2 mmole compound $4 \mathbf{a}$ or $7 \mathbf{a}$ was dissolved in $35 \mathrm{~mL}$ of dichloromethane-THF (1:1). Barium manganate $(5.6 \mathrm{~g})$ was ground to a fine powder and added immediately to the dichloromethane- 
THF solution. The mixture was stirred for two hours at room temperature. Inorganic by-products were removed by filtration of the reaction mixture through Celite. The Celite was washed with dichloromethane, the latter solution was added to the dichloromethane-THF filtrate previously obtained. Evaporation of dichloromethane-THF in vacuo gave a pale yellow residue, which was recrystallized from ethylacetate and petroleum ether to give the desired product. Specific details are given for each compound.

3,5-Diphenyl-6-methyl-4-oxo-4H-pyran-2-carboxaldehyde (3a). From $0.58 \mathrm{~g}$ of 4a, $0.56 \mathrm{~g}$ of pale yellow crystals were obtained in 97\% yield; mp 188.9-189.4 ${ }^{\circ} \mathrm{C}$ (lit. ${ }^{7} 189.0-189.6{ }^{\circ} \mathrm{C}$ ). Anal. Calcd. for $\mathrm{C}_{19} \mathrm{H}_{14} \mathrm{O}_{3}$ : C, 78.61\%; H, 4.86\%. Found: C, 78.49\%; H, 4.78\%. MS (EI, 70 ev): $\mathrm{m} / \mathrm{z}$ $290\left(\mathrm{M}^{+}\right)$. IR: 805, 982, 1260, 1645, 1700, 2810, 2925 and $3010 \mathrm{~cm}^{-1} .{ }^{1} \mathrm{H} \mathrm{NMR}\left(\mathrm{CDCl}_{3}\right): \delta 2.41$ $\left(3 \mathrm{H}, \mathrm{s},-\mathrm{CH}_{3}\right), 7.45\left(10 \mathrm{H}, \mathrm{m}\right.$, Phenyl-H), $9.80(1 \mathrm{H}, \mathrm{s},-\mathrm{CHO}) .{ }^{13} \mathrm{C} \mathrm{NMR}\left(\mathrm{CDCl}_{3}\right): \delta 21.0\left(-\mathrm{CH}_{3}\right)$, 128.1, 128.5, 129.8, 131.5 and 133.5 (Phenyl-C), 127.5 (Pyran-C-5), 130.2 (Pyran-C-3), 148.9 (Pyran-C-6), 152.9 (Pyran-C-2), 183.2 (Pyran-C-4), 201.2 (-CHO).

3,5-Diphenyl-4-oxo-4H-pyran-2,6-dicarboxaldehyde (6a). From $0.62 \mathrm{~g}$ of $7 \mathrm{a}, 0.58 \mathrm{~g}$ of pale yellow crystals were obtained in 95\% yield; mp 196.5-197.2 ${ }^{\circ} \mathrm{C}$ (lit. ${ }^{7} 196.3-196.9{ }^{\circ} \mathrm{C}$ ). Anal. Calcd. for $\mathrm{C}_{19} \mathrm{H}_{12} \mathrm{O}_{4}$ : C, 74.99\%; H, 3.97\%. Found: C, 75.12\%; H, 4.08\%. MS (EI, 70 ev): $\mathrm{m} / z$ $304\left(\mathrm{M}^{+}\right)$. IR: $1650,1700,2875$ and $3030 \mathrm{~cm}^{-1} .{ }^{1} \mathrm{H}$ NMR (acetone- $\left.d_{6}\right): \delta 7.45(10 \mathrm{H}$, m, PhenylH), $9.65(2 \mathrm{H}, \mathrm{s},-\mathrm{CHO}) .{ }^{13} \mathrm{C}$ NMR (acetone- $\left.d_{6}\right)$ : $\delta 128.4,128.9,130.3,131.5$ and 134.5 (PhenylC), 136.1 (Pyran-C-3, -5), 152.5 (Pyran-C-2,-6), 184.8 (Pyran-C-4), 206.5 (-CHO).

\section{Conclusions}

We have developed a convenient new method for the preparation of hydroxymethyl and carboxaldehyde derivatives of 3,5-diphenyl-4H-pyran-4-one substituted at positions 2 and 6 , compounds 3a, 4a, 6a and 7a. The presently described preparation method offers some advantages over previous methods. For instance, it uses a cheaper reagent and has higher total yields. Also, it is readily applicable to the large scale preparation of compounds 3a, 4a, 6a and 7a. All compounds can be used as precursors for the synthesis of host molecules.

\section{Acknowledgements}

Financial support for this work by the Research Council of Malek-ashtar University of Technology is gratefully acknowledged. The authors deeply thank Dr. L. Razmjou for her careful review. 


\section{References}

1. Moriguchi, T.; Matsuura, H.; Itakura, Y.; Katsuki, H.; Saito, H.; Nishiyama, N. Life Sci. 1997, 61, 1413.

2. Murrary, R. D. H. Aromat. Heteroaromat. Chem. 1978, 5, 472.

3. Richardo, M. A. G.; Andreo, M. A.; Cavalheiro, A. J.; Gamboa, I. C.; Bolzani, V. S.; Silva, D. H. Arkivoc 2004, 6, 127.

4. Clark, B. P.; Ross, W. J.; Todd, A. U.S. Patent 4,471,129, 1984.

5. Clark, B. P.; Ross, W. J.; Todd, A. U.S. Patent 4,364,956, 1981.

6. Soni, A. K.; Krupadanam, G. L. D.; Srimannarayana, G. Arkivoc 2006, 16, 35.

7. Shahrisa, A.; Tabrizi, R. Iran. J. Chem. \& Chem. Eng. 1999, 18, 91.

8. Shahrisa, A.; Tabrizi, R.; Ahsani, H. R. Org. Prep. \& Proced. Int. 2000, 32, 47.

9. Ghandi, M.; Bayat, Y.; Teimuri-mofrad, R. Org. Prep. \& Proced. Int. 2002, 34, 525.

10. Yachevskii, D. D.; Chizhov, D. L.; Pashkevich, K. I.; Charushin, V. N. Arkivoc 2004, 11, 71.

11. (a) EL-Naby, A.; Saad, M. Afr. J. Mycol. Biotechnol. 1996, 4, 59. (b) Sato, K.; Sakai, A. Jpn. Kokai Tokkyo Koho JP. 09,220,095, 1997; Chem. Abstr. 1997, 127, 204546h. (c) Pei, J. Shipin Yu Fajiao Gongye, 1997, 23, 11; Chem. Abstr. 1997, 127, 261753x.

12. Barton, D. H. R.; Brown, B. D.; Ridley, D. D.; Widdowson, D. A.; Keys, A. J.; Leaver, C. J. J. Chem. Soc. Perkin 1, 1975, 20.

13. Bransova, J.; Uher, M.; Brtko, J. Chem. Pap. 1994, 48, 341.

14. Bransova, J.; Uher, M.; Brtko, J. ibid. 1993, 47, 316.

15. Massa, W.; Schween, M.; Steuber, F. W.; Wocaldo, S. Chem. Ber. 1990, 123, 1119.

16. Emmick, T. L.; Letsinger, R. L. In Organic Syntheses, Collective; Baumgarten, H. E. Eds.; John Wiley \& Sons, New York, 1973; Vol. V, pp 450-2.

17. (a) Wohl, A. Chem. Ber. 1919, 52, 51. (b) Ziegler, K.; Spath, A.; Schaaf, E.; Schumann, W.; Winkelmann, F. Liebigs Ann. Chem. 1942, 551, 80.

18. Smith, M. B.; March, J. Advanced Organic Chemistry, $5^{\text {th }}$ Edn.; John Wiley \& Sons, New York, 2001; pp 462-3.

19. Pinck, L. A.; Hilbert, G. E. J. Am. Chem. Soc. 1946, 68, 751.

20. Hutchins, R. O.; Taffer, I. M. J. Org. Chem. 1983, 48, 1360.

21. Gingras, M.; Chan, T. H. Tetrahedron Lett. 1989, 30, 279.

22. Ruddick, C. L.; Hodge, P.; Houghton, M. P. Synthesis, 1996, 1359.

23. Clark, J. H.; Emsley, J.; Hoyte, O. P. A. J. Chem. Soc. Perkin 1, 1977, 1091. 